\title{
Gold CIP and CIL process optimization in a capital constraint environment
}

\author{
by C.A. Snyders*, G. Akdogan*, S.M. Bradshaw*, and \\ A.P. van Wyk*
}

\section{Synopsis}

This article focuses on the use of a model in combination with economic analysis to extract maximum value out of current gold operations, without the need for additional capital. Two South African case studies (CIP and CIL) are presented to show that an optimum point of operation exists. This optimum point of operation, however, depends on several economic factors such as the gold price, exchange rate, and utility costs in combination with plant conditions such as the feed rate and Au grade. As these parameters fluctuate, the operating conditions will have to be adjusted to achieve the maximum value. Operating at a maximum will require regular decisionmaking and adjusting of operating conditions, especially in times of a constrained economy.

Keywords

gold recovery, optimization, CIP, RIP, economic, analysis, modelling.

\section{Introduction}

The well-known carbon-in-pulp (CIP) and carbon-in-leach (CIL) gold recovery processes are fairly robust. Considering the constantly changing characteristics of run-of-mine (ROM) ore, a robust process is in general a great advantage for a mineral processing plant. The disadvantage, however, is that because less input is required from operators and metallurgical personnel, the process may not always be running under optimized conditions.

Several tools have been developed over the years to assist in achieving maximum value from the gold recovery process, including several models that can predict the leaching and adsorption of $\mathrm{Au}$ in the CIP or CIL process. These models are predominantly used by design houses to design and size the plant, and in most cases this is where the usage of these models stops. The reason for this is not clear, as an accurate CIP model will also be of great assistance in the day-to-day operation of the plant, especially in times of constantly fluctuating gold prices and exchange rates, and rapidly increasing input costs. In the past, many research investigations have focused mainly on the specific model or one of the unit processes, and not on the plant as a whole. This study, therefore, aims to make use of the well-known Nicol-Fleming first-order kinetic adsorption model (Nicol, Fleming, and
Cromberge, 1984a, 1984b, 1984c) which has been calibrated to plant data, in combination with an economic analysis in order to determine the operational conditions that will result in maximum revenue. This will also highlight the plant sensitivity to certain variables, ultimately allowing for greater plant understanding. Although this model is not the most accurate, it still predicts the gold in solution and gold on carbon profiles very well, and can be combined with economic models with relative ease to arrive at the optimum operating conditions. More accurate results will require more experimental data for the more complex and rigorous models to be used.

\section{Model development}

It is widely accepted that the performance of the adsorption circuit directly influences the elution and regeneration circuits. What is often neglected, however, is how the performance of the elution and regeneration circuit will influence the adsorption circuit. Fleming et al., (2011) state that, in order to consistently achieve low barren losses in the adsorption section, it is important to maintain a low concentration of gold on the carbon in the last adsorption stage, which effectively means that the carbon must always be eluted efficiently. Fleming et al. (2011) showed that by increasing the amount of gold on the eluted carbon being recycled to the adsorption section from zero to $50 \mathrm{~g} / \mathrm{t}$, an increase in the soluble gold losses of $370 \%$ could occur. Elution, however, takes place at a cost and an economic trade-off study is required to determine the operating point for optimum value.

The Nicol-Fleming model is one of the first and simplest models. It assumes that all tanks can be modelled as perfectly mixed reactors and that a steady-state condition with a

* Stellenbosch University, South Africa.

(c) The Southern African Institute of Mining and Metallurgy, 2017. ISSN 2225-6253. Paper received Aug. 2016; revised paper received May. 2017. 


\section{Gold CIP and CIL process optimization in a capital constraint environment}

countercurrent flow of both carbon and solution is achieved, such that the gold concentration in the solution and gold loading on the carbon can be assumed to be constant in each adsorption tank. It predicts the gold in solution and gold on carbon profiles very well, and can be combined with economic models with relative ease to arrive at the optimum operating conditions.

The rate of gold adsorption onto activated carbon is described by:

$$
\frac{d[A u]_{c}}{d t}=k\left(K[A u]_{S}-[A u]_{c}\right)
$$

This rate equation can be combined with a mass balance (Equation [2]) over the entire countercurrent CIP adsorption circuit to yield a model that can be used to describe the performance of the circuit.

$$
V_{s}\left([A u]_{s}^{0}-[A u]_{s}^{N}\right)=V_{C}\left([A u]_{c}^{0}-[A u]_{c}^{N}\right)
$$

where

$V_{S} \quad=$ Flow rate of the feed solution

$[A u] S=$ Gold concentration in the feed solution

$[A u] s^{\mathrm{N}}=$ Gold concentration in solution leaving stage $N$

$V_{C} \quad=$ Flow rate of activated carbon

$[A u] c^{\mathrm{N}}=$ Gold loading on carbon entering stage $N$

$[\mathrm{Au}] \mathrm{C}^{0}=$ Gold loading on carbon leaving the first stage

$k \quad=$ Kinetic constant

$K=$ Equilibrium constant.

Since the plant variables such as solution flow rate and grades, tank size, carbon advance rate, and carbon concentration in each tank are known, the model can be calibrated against plant data to determine both $k$ and $K$.

Nicol, Fleming, and Cromberge (1984b) also found that the method outlined above can be extended to a CIL operation by the inclusion of a leaching rate expression (Equation [3]) and assuming that the rate of leaching is independent of the activated carbon present.

$$
-\frac{d[A u]_{L, t}}{d t}=k_{L}\left([A u]_{L, t}-[A u]_{L, e}\right)^{2}
$$

where

$[A u]_{L, \mathrm{t}}=$ Concentration of the gold in the ore

$[A u]_{L, \mathrm{e}}=$ Minimum achievable residue grade

$k_{L} \quad=$ Leaching rate constant

Once both $k$ and $K$ are determined, the effect of changing an operating variable (such as the carbon advance rate) can now be determined by calculating the impact on the downstream processes, in terms of both frequency and cost. The revenue or loss incurred is calculated by Equation [4], where the variable costs are assumed to include all the costs that are affected by the changing variables. By equating the 'fixed costs' of the base case (condition where the plant normally operates) to a value that will result in zero revenue, a differential cost for each scenario can be calculated, which effectively will determine how much more revenue (or loss) can be realized by changing a certain operating variable.

Operational revenue $=$ Value of $\mathrm{Au}$ produced -

'Fixed costs' - 'Variable costs'

Case studies for both a CIP plant and a CIL plant are presented.

\section{The CIP case study}

A plant evaluation on a $180000 \mathrm{t} / \mathrm{month}$ CIP plant was performed. The plant consists of six Kemix pump cells in a carousel flow arrangement, a hydrochloric acid pre-wash, high-pressure elution at $125^{\circ} \mathrm{C}$, kiln regeneration, and electrowinning.

\section{Parameter determination and calibration}

The values for $k$ and $K$ were determined through empirical fitting by averaging plant data such as the head grade, feed flow rate, solid/liquid mass fraction and eluted carbon loadings over 3- to 5-day periods as input parameters to the model. Averages over these relative short periods were used to compensate for the leaching retention time (approx. 35 hours), the slurry retention time during adsorption, as well as the carbon retention time. Thirteen periods in total (Table I) were selected for calibration, which included periods of higher and lower feed rates and solid/liquid mass fractions. Estimated values for $k$ and $K$ were obtained from the literature (Fleming et al., 2011) and were then adapted to obtain the best fit.

The plant operates a carousel CIP circuit with three 8hour shifts and one elution per day. Carbon is transferred from the lead tank to elution at the end of the night shift or start of the morning shift, and the carbon loading is determined before elution. Carbon loadings are again determined later in the morning, afternoon, and night shifts. Since the carbon is modelled as a continuous flow (Equation [2]), the model predicts the carbon loading just prior to elution or a carbon transfer. With one elution per day, the carbon residence time for the model is therefore taken as 24 hours. An example of the plant carbon loadings in each tank for the period 1-5 December 2015 compared to the modelpredicted values can be seen in Figure 1. For this particular example, the model-predicted loading (indicated by X) compares well for stage 1 (stage before elution), stage 5 , and stage 6 while overpredicting the loading in stages 2,3 , and 4 . Predictions for the other 12 periods were found to be similar. From the six stages, the loading prior to elution is rather important as this will ultimately determine the $\mathrm{Au}$ produced after elution and electrowinning. The dotted line in Figure 1 serves as an indication of the increases in measured gold loading on the carbon throughout the day.

Figure 2 compares the Au grade in solution for each stage to the model-predicted values for the sampling period.

The model-predicted solution tails are compared to actual plant data in Table I, while the product of the adsorption constants $(k K)$ as a function of the solid/liquid mass fraction (\%) of the pulp, determined in this study, is compared to literature data in Figure 3.

Considering Figures 1 to 3 as well as Table I, the model with determined $k K$ values was deemed a reasonable theoretical representation of the specific operation that can be used to quantify the relative influence of a wide range of variables, allowing for better understanding of the plant and making it possible to optimize performance.

\section{CIP base case}

A base case representing the daily operation of the plant was chosen. The operating parameters for this base case are shown in Table II. The corresponding variable costs, 


\section{Gold CIP and CIL process optimization in a capital constraint environment}
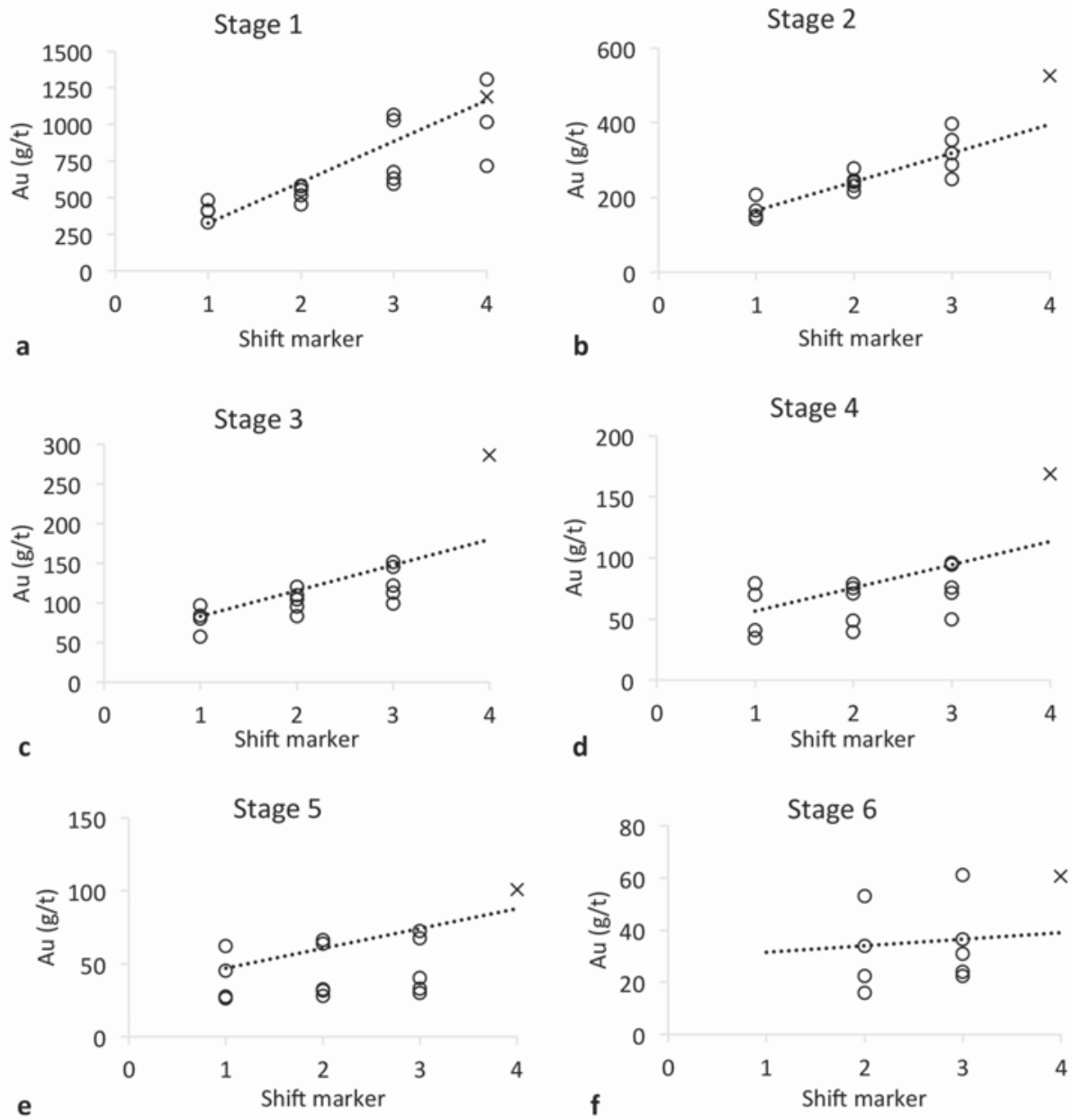

Figure 1-Predicted vs measured carbon loadings for each adsorption stage (a to f) and shift (x-axis) 1: morning shift, 2: afternoon shift, 3: night shift. 4: prior to elution, O: measured values, dotted line: measured value trend line, $\mathrm{X}$ : model prediction)

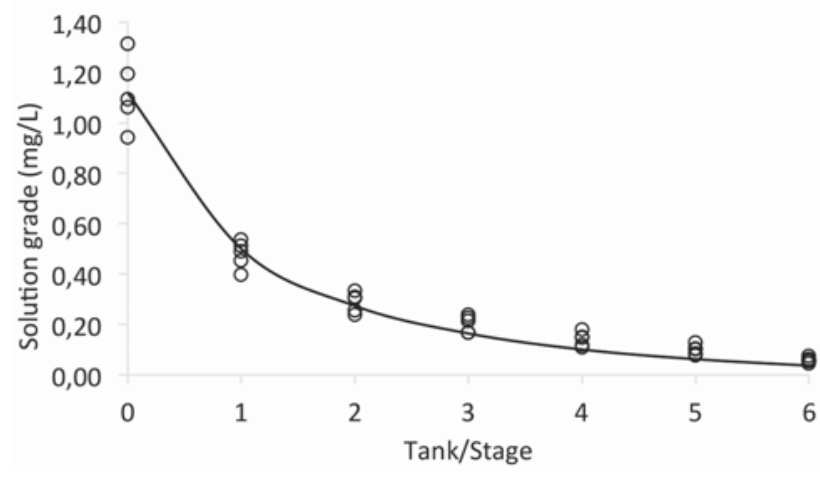

Figure 2-Predicted vs measured solution grade (1-5 December 2015) in each stage of the carbon adsorption circuit, with stage 0 being the $\mathrm{Au}$ feed grade to the first adsorption tank and stage 6 the tails. The model predictions are depicted by the line, and the plant measurements by the circles

determined from plant data, are shown in Table III. Unless otherwise stated, these conditions will be used in all cases.

With the base case set, and using the model representing plant conditions, the effect of changing operating parameters (carbon advance rate, elution efficiency, carbon concentration, gold grade, solid/liquid mass fraction and feed flow rate) was determined.

\begin{tabular}{|c|c|c|c|}
\hline \multirow[b]{2}{*}{ Date } & \multicolumn{3}{|c|}{ Au losses (mg/L) } \\
\hline & $\begin{array}{c}\text { Average of } \\
\text { actual }\end{array}$ & $\begin{array}{c}\text { St. dev of } \\
\text { actual }\end{array}$ & Predicted \\
\hline 17-19 Mar 2015 & 0.07 & \pm 0.006 & 0.09 \\
\hline 16-18 Jun 2015 & 0.05 & \pm 0.005 & 0.02 \\
\hline 21-25 Jun 2015 & 0.08 & \pm 0.036 & 0.09 \\
\hline 31 Oct-3 Nov 2015 & 0.05 & \pm 0.007 & 0.04 \\
\hline 5-7 Nov 2015 & 0.07 & \pm 0.009 & 0.07 \\
\hline 8-10 Nov 2015 & 0.06 & \pm 0.008 & 0.05 \\
\hline 11-13 Nov 2015 & 0.05 & \pm 0.004 & 0.05 \\
\hline 26-30 Nov 2015 & 0.04 & \pm 0.008 & 0.05 \\
\hline 1-5 Dec 2015 & 0.06 & \pm 0.010 & 0.04 \\
\hline 6-10 Dec 2015 & 0.06 & \pm 0.007 & 0.06 \\
\hline 11-15 Dec 2015 & 0.05 & \pm 0.009 & 0.06 \\
\hline 16-20 Dec 2015 & 0.06 & \pm 0.005 & 0.06 \\
\hline 21-24 Dec 2015 & 0.06 & \pm 0.004 & 0.06 \\
\hline
\end{tabular}

\section{Carbon advance rate}

The carbon advance rate or carbon residence time is one of the easiest parameters to change on the plant and will basically determine the amount of $\mathrm{Au}$ the carbon is loaded to before elution takes place (upgrade ratio). As per Table III, 


\section{Gold CIP and CIL process optimization in a capital constraint environment}

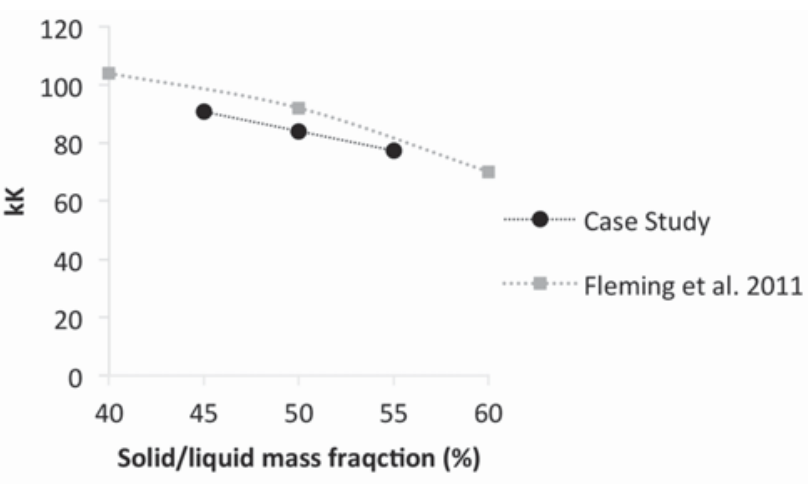

Figure 3-Plant-determined $k K$ values compared to values from Fleming

et al. (2011)

\section{Table /I}

\section{Base case conditions for the CIP case study}

\section{Feed flow rate}

Solids percentage

Adsorption tank size

Stages

Carbon retention time per stage

Carbon concentration

Carbon loading after elution

Au solution feed grade

Au price

Exchange rate

\begin{tabular}{c|c}
230 & $\mathrm{t} / \mathrm{h}$ \\
50 & $\%$ \\
100 & $\mathrm{~m}^{3}$ \\
6 & \\
24 & $\mathrm{~h}$ \\
45 & $\mathrm{~g} / \mathrm{L}$ \\
40 & $\mathrm{~g} / \mathrm{t}$ \\
1 & $\mathrm{mg} / \mathrm{L}$ \\
1250 & $\mathrm{US} \$ / \mathrm{oz}$ \\
15.4 & $\mathrm{R} / \mathrm{US} \$$
\end{tabular}

Table III

\section{Variable costs for the base case CIP operation}

\begin{tabular}{l|c|c}
\hline Variable costs & R/day & R/ton carbon \\
Acid washing & $\mathrm{R} 186$ & $\mathrm{R} 31$ \\
Elution & $\mathrm{R} 41926$ & $\mathrm{R} 6988$ \\
Regeneration & $\mathrm{R} 4455$ & $\mathrm{R} 743$ \\
Electrowinning & $\mathrm{R} 211$ & $\mathrm{R} 35$ \\
Carbon breakage & $\mathrm{R} 2615$ & \\
Gold on carbon fines loss & $\mathrm{R} 2166$ & \\
\hline Total variable cost & $\mathrm{R} 51558$ &
\end{tabular}

the costs of elution, acid washing and regeneration are major contributors to the variable cost. This cost can immediately be reduced by increasing the carbon residence time, which will increase the carbon loading and decrease the frequency of elution and regeneration. These costs are, however, offset by the adsorption capacity of the higher-loaded carbon, which will cause an increase in the gold losses to the tailings. Figures $4 \mathrm{a}$ and $4 \mathrm{~b}$ show the effect of the carbon residence time on the differential revenue/loss as well as the change in variable cost and $\mathrm{Au}$ loss to the tailings.

Even though the plant is well designed and operating within the design parameters, by reducing the carbon residence time in each tank from 24 hours to 17 hours, an additional R10 000 per day may be realized, resulting in approximately R 3.3 million per annum for a 330-day operating year. The carbon loadings will reduce from approximately $1200 \mathrm{~g} / \mathrm{t}$ for the base case to $880 \mathrm{~g} / \mathrm{t}$ for a residence time of 17 hours, while the $\mathrm{Au}$ in solution to the tailings should decrease from $0.051 \mathrm{mg} / \mathrm{L}$ to $0.042 \mathrm{mg} / \mathrm{L}$. This decrease in $\mathrm{Au}$ in the solution tails is the primary reason for the increased revenue. The revenue and optimum point of operation determined here are, however, associated with a specific Au price and rand/dollar exchange rate, both of which have been known to fluctuate quite dramatically. Figure 5a shows how the point of optimum performance in terms of carbon residence time shifts with a fluctuating $\mathrm{Au}$ rand value. For an $\mathrm{Au}$ price of $\$ 1100$ per ounce with a rand/dollar exchange rate of 13.3 (early September 2015), the optimum carbon residence time would have been 19-20 hours. As the value of the Au increases in rand terms, the optimum carbon residence time will shift to more frequent elution and can make a difference of several thousand rand per day or several million rand per annum.

Figure $5 \mathrm{~b}$ shows the effect of increasing electricity costs on the plant. An increase in the electricity cost of 6 cents per $\mathrm{kWh}$ will shift the optimum residence time from 17 hours to 18 hours. A change in actual operation here is probably not warranted, but it does demonstrate the sensitivity of the plant to certain parameters and therefore assists in decisionmaking. Both Figures $5 \mathrm{a}$ and $5 \mathrm{~b}$ illustrate that operating the process at a constant set of conditions will not result in optimum revenue, but the conditions rather need to be
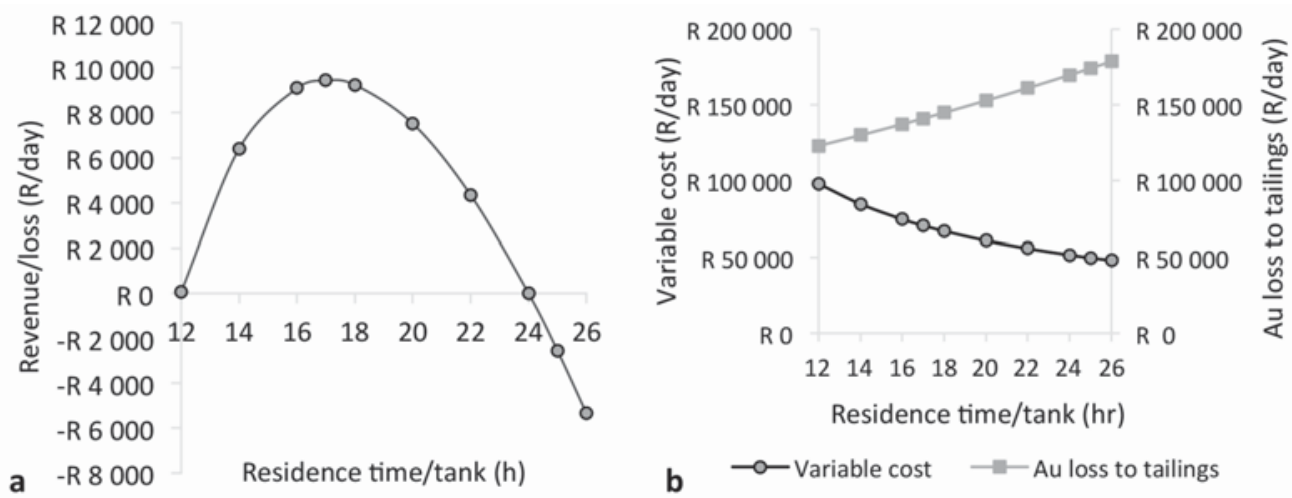

Figure 4-(a) The differential daily revenue/loss with varying carbon residence time compared to the current operation at 24 hours, and (b) the associated operational costs and Au value loss to the tailings 


\section{Gold CIP and CIL process optimization in a capital constraint environment}
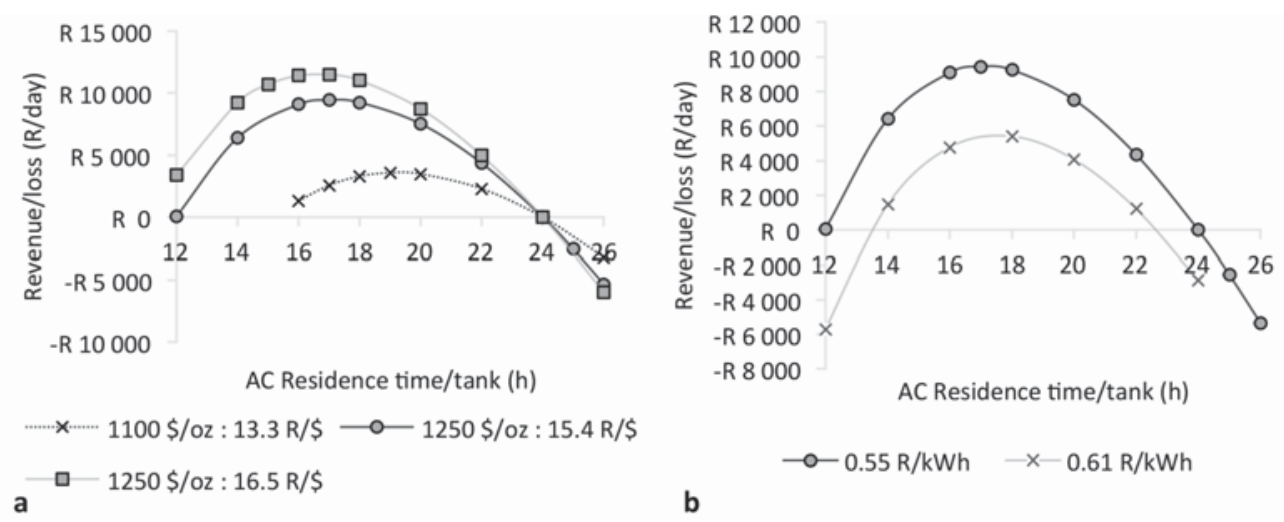

Figure 5-Determination of the optimum carbon residence time for (a) fluctuating rand/dollar exchange rate and Au price and (b) electricity costs
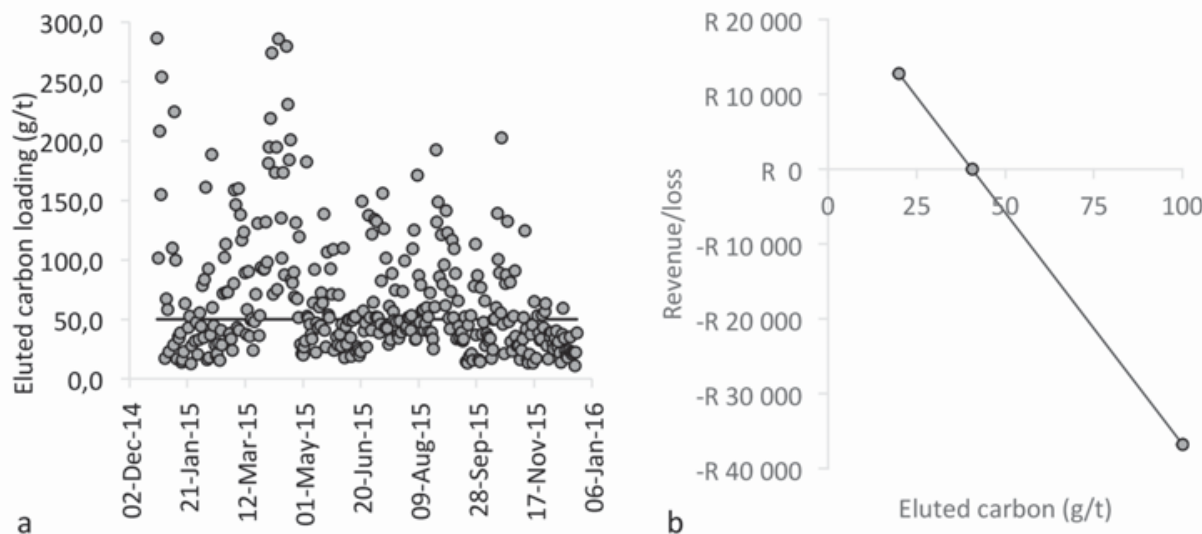

Figure 6-(a) Operational carbon loadings after elution, and (b) the impact on the differentail revenue/loss per day, assuming the base case at $40 \mathrm{~g} / \mathrm{t}$ carbon loading after elution

adapted when any of the costs (including raw materials, utilities, and labour) changes.

Operational changes such as these, however, may often fall outside the bounds of practicality or plant limitations, and it may be argued that changing operational parameters on the plant is not that easy. Some of this operational problems may lie with the management of the plant and how quickly and easily decisions are communicated and then carried out. Other limitations may be a result of the installed process, such as the time it takes for effective elution to take place (Zadra or AARL). In such instances, the focus will first have to shift to reducing the elution time without sacrificing efficiency; or if the process is already at an optimum, determining whether it will be worthwhile to install another elution column, for example.

\section{Elution efficiency}

The importance of efficient elution and the impact on the adsorption section in terms of potential gold losses have already been stated. Figure $6 \mathrm{a}$ indicates the achieved elution efficiencies of the present case study in terms of the $\mathrm{Au}$ loading on the carbon being recycled to the adsorption section (straight line at $50 \mathrm{~g} / \mathrm{t}$ as set target), while Figure $6 \mathrm{~b}$ highlights the importance of efficient elution for the daily revenue of the plant (base case carbon loading of $40 \mathrm{~g} / \mathrm{t}$ assumed after elution). No apparent reason for the less efficient elution (or highly efficient elution $(<25 \mathrm{~g} / \mathrm{t})$ ) in Figure $6 \mathrm{a}$ could be determined from the plant data or operating practices, and as such no additional costs were included in the derivation of Figure $6 \mathrm{~b}$ to achieve the more efficient elution. Determining how to achieve consistently low carbon loadings will, however, be crucial for improving the accuracy of the model and optimizing profitability. In addition, it is also important to realize that once poor elution has occurred, the high temperatures (approx. $750^{\circ} \mathrm{C}$ ) in the regeneration kiln will convert some or all of the gold cyanide complexes on the activated carbon to Au particles (Oladele, Snyders, and Bradshaw, 2015), which will require more stringent conditions to elute.

\section{Carbon concentration}

The effect of carbon concentration is shown in Figure 7.

A disadvantage of increasing the carbon concentration is that more fines will be generated in the circuit, which leads to higher gold losses on these carbon fines. The amount of fines generated will be different for each plant, and due to the lack of data for this specific case study, values from literature (Baily, 1991) were used. It was also assumed that the Au loading on the carbon fines will be similar to the carbon loadings in the last stage of adsorption, due to equilibrium being reached between the carbon fines and larger size fractions when mixed (Nicol, Fleming, and 


\section{Gold CIP and CIL process optimization in a capital constraint environment}

Cromberge, 1984c). This loss is depicted in Figure 7b, which shows the increasing variable cost that will result due to an increase in the carbon concentration in each tank. The increasing cost, however, does not outweigh the decrease in $\mathrm{Au}$ loss to the tailings due to improved adsorption, and the plant revenue will therefore increase with the higher carbon concentration. In this case the carbon concentration is limited by the size of the elution column ( $5 \mathrm{t}$ ) and is therefore the maximum concentration achievable without any additional capital requirements.

With the higher carbon concentration, the optimum carbon residence time now also shifts to the right, and was found to be 20 hours with a carbon loading of approximately $940 \mathrm{~g} / \mathrm{t}$ and a tailings grade of $0.036 \mathrm{mg} / \mathrm{L}$.

\section{Gold grade}

Except for a blending strategy and perhaps some influence in ore selection, plants usually have limited control over the feed $\mathrm{Au}$ grade and simply have to treat what is being fed to the plant. It is in this sense that the carbon process is fairly robust, since extraction efficiencies will remain high with variation in Au grade. Figure 8 shows the impact of carbon residence time on the optimum performance of the plant when the Au grade changes from $0.5 \mathrm{mg} / \mathrm{L}$ to $2.3 \mathrm{mg} / \mathrm{L}$. The feed grades to the plant have varied within this range at certain periods within a timespan of a year. While the impact of operating with a sub-optimum carbon residence time with an $\mathrm{Au}$ feed grade of $0.5 \mathrm{mg} / \mathrm{L}$ is minimal, significant value can be realized by adapting the carbon advance rate for higher Au feed grades.

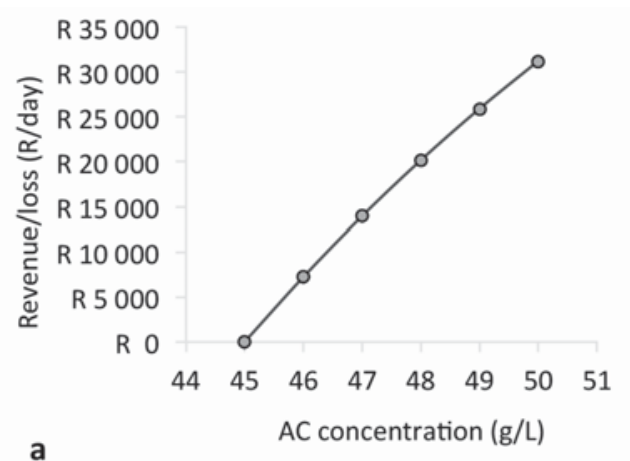

Eluting every 22 to 23 hours for a feed grade of $0.5 \mathrm{mg} / \mathrm{L}$ results in a gold loading of approximately $600 \mathrm{~g} / \mathrm{t}$ with a tailings grade of $0.028 \mathrm{mg} / \mathrm{L}$, while at $2.3 \mathrm{mg} / \mathrm{L}$ feed grade the carbon will be loaded to approximately $1380 \mathrm{~g} / \mathrm{t}$ with a tailings grade of $0.073 \mathrm{mg} / \mathrm{L}$. To reduce this tailings grade even further, the carbon concentration can be increased as indicated in the previous section.

\section{Solid/liquid mass fraction}

As regards the solid/liquid mass fraction of the feed pulp, two main scenarios can be considered. The first scenario assumes that the dry tons feed flow rate to the adsorption section remains constant while the effect of the solid-liquid mass fraction is being considered. With the dry tonnage feed flow rate to the plant remaining constant, a higher solids mass fraction will result in the slurry flow rate decreasing and the slurry residence time per tank increasing. The second scenario (usually the option that most plants would consider) takes advantage of the lower slurry flow rate and increases the dry tonnage feed rate to a point where the slurry residence time remains constant. Since the second scenario requires a much wider investigation, which needs to include the cost of crushing, milling, and leaching, which were not part of the initial investigation, this scenario was not considered further.

Figure 9 shows the results on the differential revenue/loss for scenario 1. Figure 9 is based on the assumption that leaching is not affected and that the same amount of $\mathrm{Au}$ is leached with less dilution, resulting in a higher solution feed grade to the adsorption section. Even

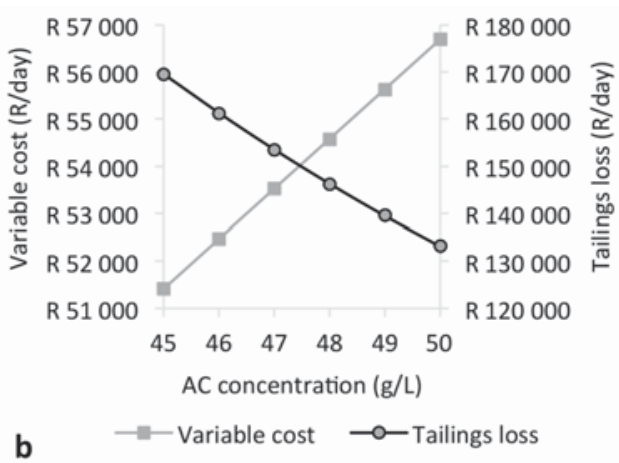

Figure 7-(a) The effect of carbon concentration on differential revenue/loss per day, and (b) the operating cost and Au loss to tailings
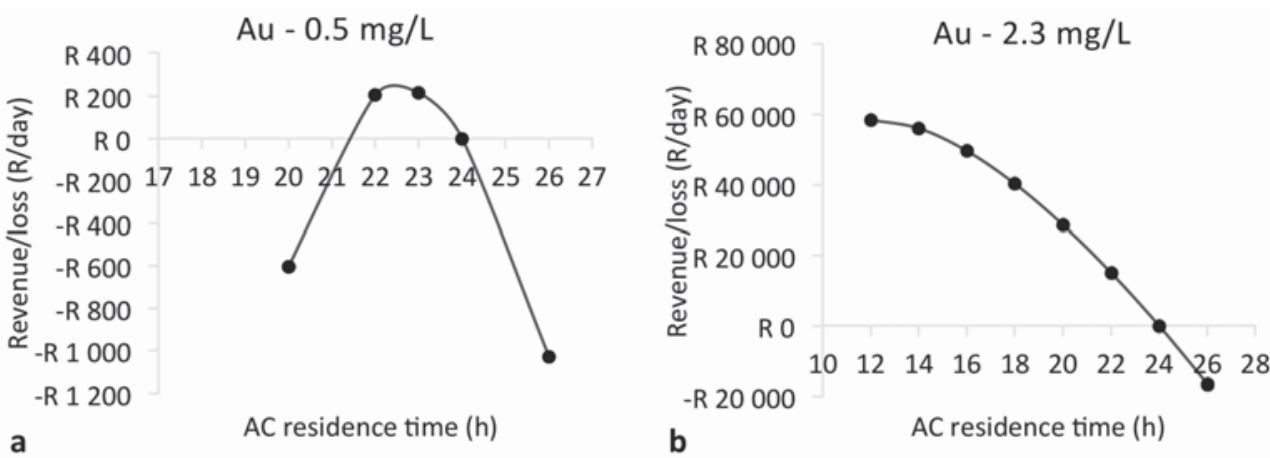

Figure 8-The effect of Au feed grade on the optimum carbon residence time 


\section{Gold CIP and CIL process optimization in a capital constraint environment}

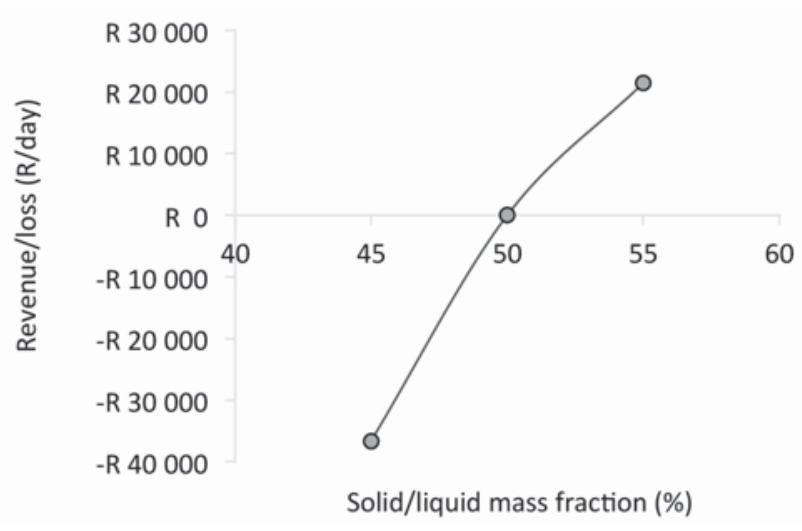

Figure 9-The effect of the solid/liquid mass fraction on the differential plant revenue/loss with a constant dry tonnage feed

though the adsorption constants for the higher solids concentration are lower (Figure 3), the combination of the higher solution grade and the lower solution flow rate will result in a higher adsorption driving force, with ultimately less $\mathrm{Au}$ loss to the tailings.

\section{Feed flow rate}

According to Figure 10a, feed flow rates to the adsorption section can vary quite significantly, between 200 and $300 \mathrm{t} / \mathrm{h}$. The effect of the different flow rates is shown in Figure 10b. For each flow rate, the revenue/loss was set to zero at 24 hours carbon residence time and the flow rates cannot, therefore, be directly compared. The figure does, however, illustrate that the higher the feed rate, the more frequently elution needs to take place. The cost benefit also increases with flow rate, and it is shown that an additional R25 000 per day could have been realized if elution took place every 14 hours when the plant was operating at $250 \mathrm{t} / \mathrm{h}$. During times of lower feed rate (start-up for example), less frequent elution is advised.

The high variability in the actual plant operating conditions, as indicated by Figure 6 as well as Figure 10, also offers an equal opportunity for revenue improvement if these variables can be stabilized. Making regular changes to the operating variables increases the risk of introducing further instability, which can lead to losses.

\section{Optimized conditions}

The impact of carbon residence time, carbon concentration, and solids-liquid ratio on the differential revenue for this case study is shown in Figure 11. Operating the plant at a carbon concentration of $50 \mathrm{~g} / \mathrm{L}$, at $55 \%$ solids, and eluting every 22 hours has the potential of adding R50 000 per day or R16.5 million per 330-day work year to the balance sheet without any capital requirements.
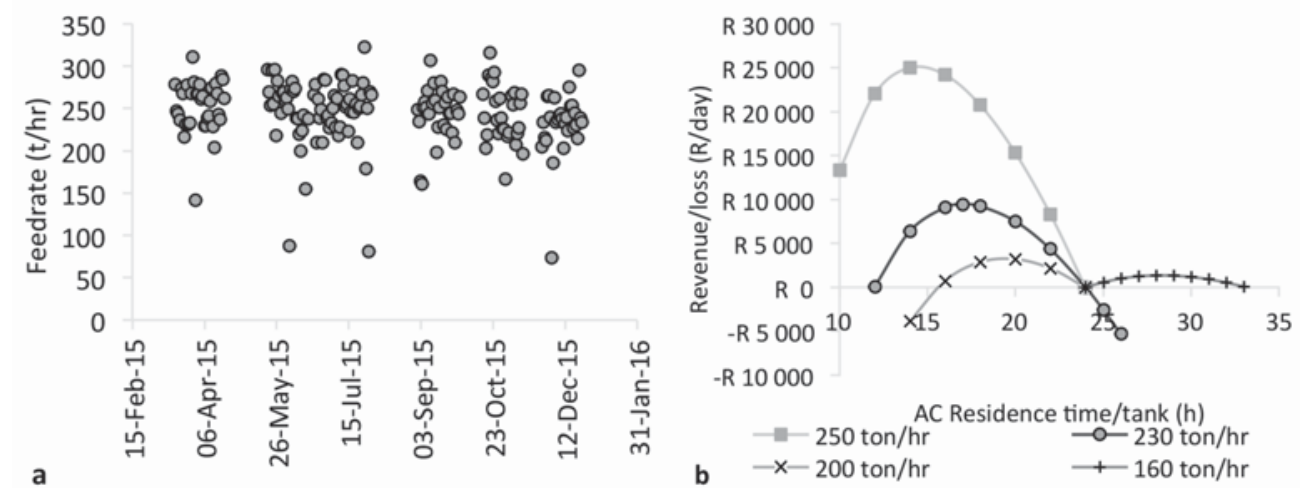

Figure 10-(a) Actual CIP plant feed rates, and (b) the optimum carbon residence times for these feed rates

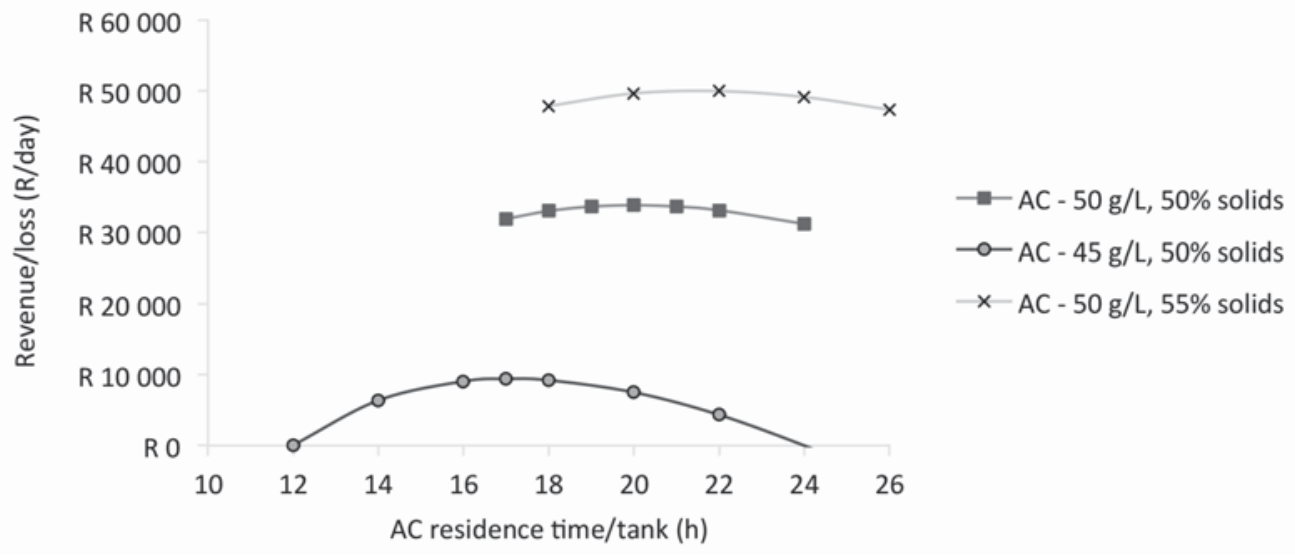

Figure 11-The impact of carbon residence time, carbon concentration, and the solids-liquid ratio on the differential revenue of the plant 


\section{Gold CIP and CIL process optimization in a capital constraint environment}

\section{CIL case study}

The second case study focused on a much smaller CIL plant, which consists of six conventional cells, all containing carbon, a hydrochloric acid pre-wash, high-pressure elution at $110^{\circ} \mathrm{C}$, kiln regeneration, and electrowinning.

\section{Model calibration}

The values for $k, K$, and $k_{L}$ as per Equations [1], [2], and [3], were determined through empirical fitting by averaging plant data over 3 days as input parameters to the model. The data fitting is shown in Figures 12a to $12 \mathrm{~d}$.

The model-predicted solution tails losses are compared to actual plant data in Table IV, and the model-predicted gold produced compared to actual gold produced in Table $\mathrm{V}$.

The predictions are less accurate than those in the CIP case study. This may be attributed to the consistently changing nature of the feed material for the CIL plant, which treats a combination of scrap material for other plants as well as re-treating old tailing dumps.

\section{CIL base case}

As per the previous case studies, the plant was evaluated by determining the differential revenue or loss that can be realized if some of the operating parameters are changed. The parameters for the base case of the operation (Table VI) and the corresponding variable costs (Table VII) were determined; unless otherwise stated, these conditions will be used in all cases.

\section{Carbon advance rate and elution efficiency}

Similar to the first case study, the optimum carbon advance rate was determined by calculating the differential revenue or loss to the plant if the carbon residence time is to change. Since a conventional flow arrangement (instead of the carousel arrangement) is employed, only a portion of the carbon can be pumped to elution, and therefore the carbon advance rate is controlled based on the amount of carbon sent to elution each day. The plant target is elution of 1000 $\mathrm{kg}$ of carbon per day, or one elution daily ( $1 \mathrm{t}$ column). To remain consistent with plant practice, the carbon advance rate is reported in a similar format for this case study.

Figure 13 indicates that it will be beneficial to slow the carbon advance rate and elute less frequently. With a carbon advance rate of $1000 \mathrm{~kg}$ being eluted each day, the corresponding Au loading on the carbon is only
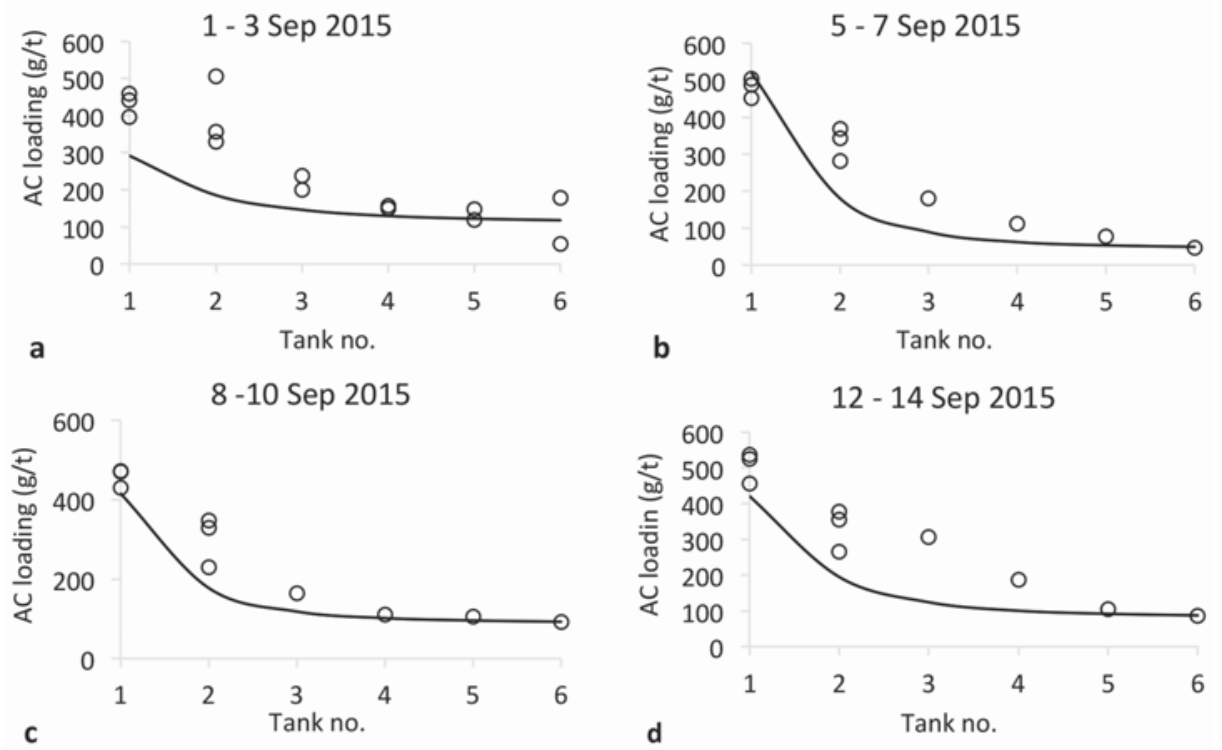

Figure 12-Predicted vs measured carbon loadings in each stage of the CIL circuit

\begin{tabular}{|l|c|c|}
\hline \begin{tabular}{l} 
Table IV \\
Predicted vs actual Au lost to tailings \\
\hline
\end{tabular} & $\begin{array}{c}\text { Tailings losses } \\
\text { (mg/L) }\end{array}$ & $\begin{array}{c}\text { Predicted tailings } \\
\text { losses (mg/L) }\end{array}$ \\
\hline & 0.025 & 0.024 \\
1-3 Sep 2015 & 0.015 & 0.011 \\
5-7 Sep 2015 & 0.016 & 0.018 \\
8-10 Sep 2015 & 0.029 & 0.019 \\
12-14 Sep 2015 & 0.032 & 0.031 \\
15-17 Sep 2015 & 0.048 & 0.023 \\
19-21 Sep 2015 & 0.053 & 0.023 \\
22-24 Sep 2015 & 0.054 & 0.025 \\
26-28 Sep 2015 & & \\
\hline
\end{tabular}

\begin{tabular}{|c|c|c|}
\hline \multicolumn{3}{|c|}{$\begin{array}{l}\text { Table } V \\
\text { Predicted vs actual Au produced per day }\end{array}$} \\
\hline & $\begin{array}{c}\text { Actual Au } \\
\text { produced (g/day) }\end{array}$ & $\begin{array}{c}\text { Predicted Au } \\
\text { (g/day) }\end{array}$ \\
\hline 1-3 Sep 2015 & 162 & 149 \\
\hline 5-7 Sep 2015 & 471 & 459 \\
\hline 8-10 Sep 2015 & 234 & 269 \\
\hline 12-14 Sep 2015 & 292 & 284 \\
\hline 15-17 Sep 2015 & 278 & 267 \\
\hline 19-21 Sep 2015 & 253 & 254 \\
\hline 22-24 Sep 2015 & 372 & 365 \\
\hline 26-27 Sep 2015 & 247 & 249 \\
\hline
\end{tabular}




\section{Gold CIP and CIL process optimization in a capital constraint environment}

\begin{tabular}{|c|c|c|}
\hline \multicolumn{3}{|l|}{ Table VI } \\
\hline \multicolumn{3}{|c|}{ Base case conditions for the CIL case study } \\
\hline Feed flow rate & 10 & $\mathrm{t} / \mathrm{h}$ \\
\hline Solid/liquid mass fraction & 50 & $\%$ \\
\hline Adsorption tank size & 95 & $\mathrm{~m}^{3}$ \\
\hline Stages & 6 & \\
\hline Carbon retention time per stage & 48 & $\mathrm{~h}$ \\
\hline Carbon concentration & 20 & $g / L$ \\
\hline Carbon loading after elution & 45 & $\mathrm{~g} / \mathrm{t}$ \\
\hline Elution column & 1 & ton \\
\hline Au price & 1100 & US\$/oz \\
\hline Exchange rate & 16.5 & $\mathrm{R} / \mathrm{US} \$$ \\
\hline
\end{tabular}

\begin{tabular}{|l|c|}
\hline \multicolumn{2}{|l|}{ Table VII } \\
Variable costs for the base case CIL operation \\
\hline Operating costs & R/day \\
\hline Acid washing & $\mathrm{R} 680$ \\
Elution & $\mathrm{R} 9855$ \\
Regeneration & $\mathrm{R} 1494$ \\
Electrowinning & $\mathrm{R} 201$ \\
Carbon breakage & $\mathrm{R} 4$ \\
\hline Total operating cost & $\mathrm{R} \mathbf{1 2} \mathbf{2 3 5}$ \\
\hline
\end{tabular}
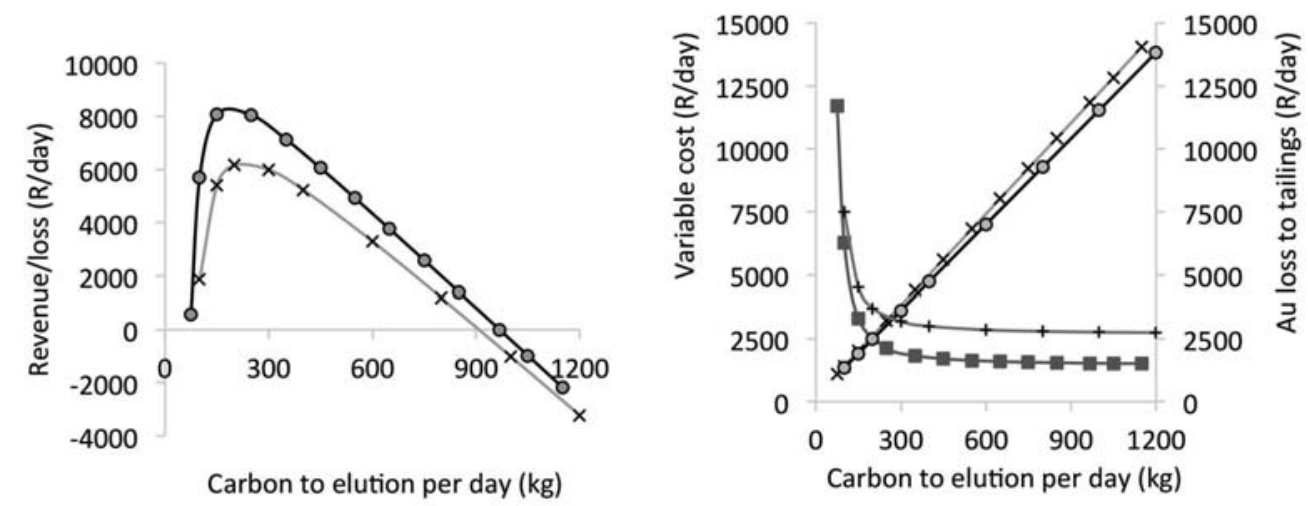

Carbon to elution per day $(\mathrm{kg})$

a

$\rightarrow-45 \mathrm{~g} / \mathrm{t} \rightarrow-100 \mathrm{~g} / \mathrm{t}$

$-x-$ Variable cost $-45 \mathrm{~g} / \mathrm{t} \rightarrow-$ Talings lost $-45 \mathrm{~g} / \mathrm{t}$
b - - Variable cost $-100 \mathrm{~g} / \mathrm{t} \rightarrow$ Tailings loss $-100 \mathrm{~g} / \mathrm{t}$

Figure 13-(a) The differential daily revenue/loss with varying carbon advance rates, and (b) the associated operational costs and Au value loss to the tailings for both a high-efficiency elution $(45 \mathrm{~g} / \mathrm{t})$ and a lower efficiency elution $(100 \mathrm{~g} / \mathrm{t})$

approximately $520 \mathrm{~g} / \mathrm{t}$. Eluting every second day $(500 \mathrm{~kg}$ to elution per day), will result in an increase of the carbon loading to approximately $960 \mathrm{~g} / \mathrm{t}$, and $1500 \mathrm{~g} / \mathrm{t}$ for every third day (330 kg to elution per day). It is important, however, to realize that these values were calculated by assuming that the $k$ and $K$ values (indicating Au adsorption) will remain constant regardless of the time the carbon spent in the circuit, and do not take into account the potential for increased carbon poisoning with time. Since the effect of carbon poisoning on the adsorption constants is currently not known, but will require a separate dedicated study, a conservative approach is recommended when decreasing the carbon advance rate. The potential cost benefit of less frequent elution for this case study is clear, however.

Figure 13 also shows the effect of elution efficiency on the differential revenue to the plant. In this case, it was assumed that whenever a less efficient elution was performed, it was due to a shorter elution cycle that used less water and energy. Figure 13b shows the impact of a shorter elution cycle on the variable cost compared to the increased tailings loss as a result of the less efficient elution. Although the impact is less than in the CIP case study, due to the CIL plant being much smaller with much reduced feed flow rates, it still shows that a high elution efficiency will be beneficial to the cost balance sheet.

\section{Carbon concentration}

The effect of carbon concentration is shown in Figure 14a. In this case, it is beneficial to increase the carbon concentration from $20 \mathrm{~g} / \mathrm{L}$ to $30 \mathrm{~g} / \mathrm{L}$, where revenue reaches a plateau and any additional increase in carbon concentration will not add further value. This plateau is due to leaching and adsorption taking place concurrently in the CIL circuit. Adding more carbon to enhance adsorption while the leaching remains slow, will therefore not increase value.

\section{Carbon profile}

The actual plant carbon profile for the six tanks was reviewed. The carbon concentration in the lead tank (tank 1) was found to be consistently higher than for tank 6 . An example of this profile is shown in Figure 15a. The impact of the carbon profile was modelled and the results are shown in Table VIII. Figure 15a shows the carbon profile, while Figure $15 \mathrm{~b}$ shows the change in solution concentration.

The benefit of equal amounts of carbon per tank, as well as the swopped carbon profile, lies in the higher amount of carbon in tank 6, which prevents Au losses to the tailings. For the equal and swopped carbon profiles, a higher $\mathrm{Au}$ solution concentration in the first two tanks (as per Figure $15 \mathrm{~b}$ ) occurs and the risk of preg-robbing by natural carbon fines increases (the primary reason for a CIL circuit).

\section{Conclusion}

Two case studies (CIP and CIL processes) were simulated to determine the sensitivity of the plant to certain changing variables. These were combined with an economic analysis to 


\section{Gold CIP and CIL process optimization in a capital constraint environment}
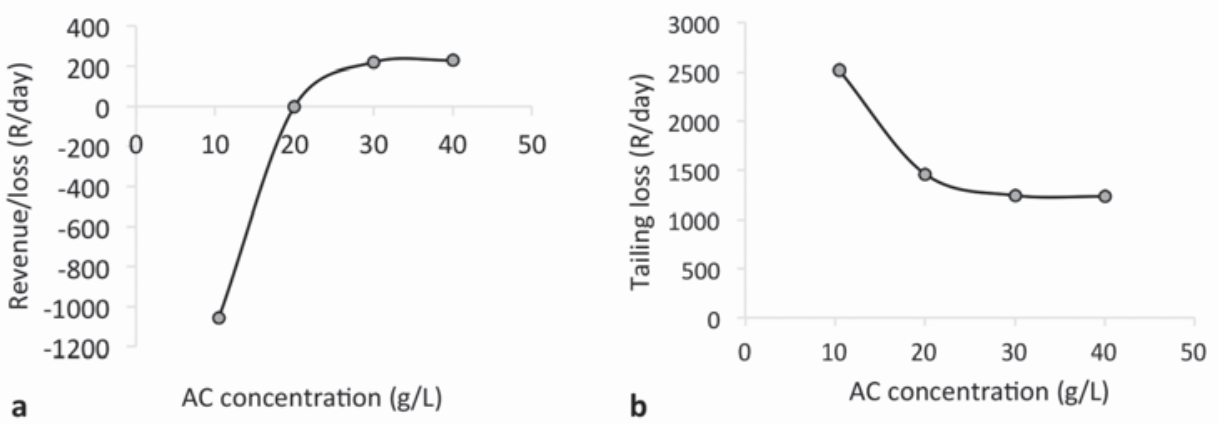

Figure 14-(a) The effect of carbon concentration on differential revenue/loss per day, and (b) Au loss to tailings
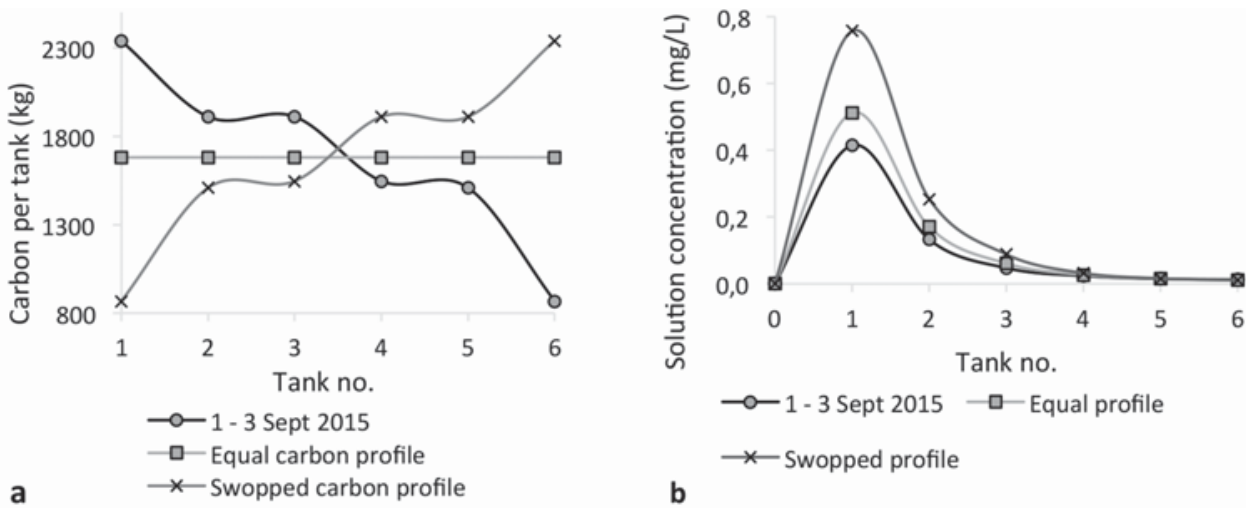

Figure 15-(a) Carbon profile for the six tanks, and (b) effect of the carbon profile on the Au solution concentration

Table VIII

\section{Differential revenue with regard to changing the carbon profile through the six tanks}

\begin{tabular}{|l|c|c|}
\hline & Revenue/loss (R/day) & Revenue (R/year) \\
\hline 1-3 Sep 2015 & R0 & R0 \\
Equal carbon profile & R228 & R75 153 \\
Swopped carbon profile & R303 & R100 003 \\
\hline
\end{tabular}

determine the operating parameters that yield the highest value. For both case studies, additional value could be realized without any additional capital requirements by adjusting the frequency of elution, carbon concentration, and the solid/liquid mass fraction of the feed. To achieve maximum value, the operating conditions need to be monitored and readjusted, if required, as they are strongly dependent on both extrinsic (commodity prices and inflation) and intrinsic factors (feed rate, gold grade, elution efficiency).

\section{Acknowledgments}

The authors would like to thank the respective plants for their assistance and provision of the plant data.

\section{References}

BAILY, P.R. 1991. Adsorption plant design. Proceedings of Recent Developments in In-Pulp Technology, Randburg, South Africa, 7-8 October 1991. South African Institute of Mining and Metallurgy, Johannesburg.
Fleming, C.A., Mezei, A., Bourricaudy, E., Canizares, M., and Ashbury, M. 2011 Factors influencing the rate of gold cyanide leaching and adsorption, and their impact on the design of CIL and CIP circuits. Minerals Engineering, vol. 24 , no. 6. pp. 484-494.

Nicol, M.J., Fleming, C.A., and Cromberge, G. 1984a. The adsorption of gold cyanide onto activated carbon. I. The kinetics of adsorption from pulps. Journal of the South African Institute of Mining and Metallurgy, vol. 84, no. 2 . pp. $50-54$.

Nicol, M.J., Fleming, C.A., and Cromberge, G. 1984b. The adsorption of gold cyanide onto activated carbon. II. The kinetics of adsorption from pulps. Journal of the South African Institute of Mining and Metallurgy, vol. 84, no. 3. pp. 70-78.

Nicol, M.J., Fleming, C.A., and Cromberge, G. 1984c. The adsorption of gold cyanide onto activated carbon. III. Factors influencing the rate of loading and the equilibrium capacity. Journal of the South African Institute of Mining and Metallurgy, vol. 84, no. 4. pp. 85-93.

Oladele, T.P., SNyders, C.A., and Bradshaw, S.M. 2015. The effect of temperature, contact time and agitation speed during pre-treatment on gold elution. Proceedings of World Gold 2015, Misty Hills, Muldersdrift, Gauteng, South Africa, 29 September - 1 October 2015. Southern African institute of Mining and Metallurgy, Johannesburg. 